\title{
MODALIDADES DIDÁTICAS: A LEITURA EM VOZ ALTA DE TEXTOS LITERÁRIOS EM FOCO
}

\author{
Jhecy Caroline Aono (Pedagogia - FACCAT)
}

Prof $^{\mathrm{a}}$. Dr ${ }^{\mathrm{a}}$. Luciana Ferreira Leal (Orientadora)

\section{RESUMO}

Este trabalho consiste em um instrumento de reflexão sobre a discussão da temática do ensino de leitura nas escolas. Por se acreditar que o docente é o principal agente mediador da formação de leitores críticos, percorremos o percurso histórico da leitura em voz alta e consideramos as modalidades didáticas de leitura que garantem a eficácia na formação de leitores autônomos. Para isso, adotamos como referenciais teóricos alguns autores que subsidiam as práticas escolares. Este trabalho descreve e analisa o processo de formação de leitores de estudantes de uma turma de $2^{\circ}$ ano do Ensino Fundamental dos anos iniciais de uma escola municipal de Tupã, por meio da modalidade didática "leitura em voz alta realizada pelo professor", objetivando, especificamente, averiguar a prática leitura em voz alta realizada pelo professor, como modalidade didática fundamental, na construção da proficiência leitora dos alunos. Esta pesquisa possibilita análise sobre os dados coletados e socialização da base teórica que a sustenta, os aspectos abordados aqui destacam a relevância de atividade que, contemplada na rotina escolar, proporciona conhecimentos fundamentais para formação de bons leitores, capazes de compreender, escolher e ler bons textos.

Palavras-chave: leitura em voz alta; docente; modalidades didáticas; proficiência leitora.

\section{A LEITURA EM VOZ ALTA DE TEXTOS LITERÁRIOS: ASPECTOS DA PESQUISA DESENVOLVIDA}

O desenvolvimento deste trabalho objetiva averiguar a prática leitura em voz alta realizada pelo professor, como modalidade didática fundamental, na construção da proficiência leitora dos alunos das séries iniciais.

Para a realização desse projeto, que visa uma investigação didática, inicialmente, utilizamos a pesquisa bibliográfica, a qual possibilita fundamento teórico, pois, como afirma Lakatos e Marconi (1991, p. 183) "[...] a pesquisa bibliográfica não é mera repetição do que já foi dito ou escrito sobre certo assunto, mas propicia o exame de um tema sob novo enfoque ou abordagem, chegando a conclusões inovadoras". No segundo momento, utilizamos a pesquisa de campo, que conforme Lakatos e Marconi (1991, p.186): “(...) é aquela utilizada com o objetivo de conseguir informações acerca de um problema, para o qual se procura uma resposta, ou de uma hipótese que se queria comprovar, e ainda descobrir novos fenômenos ou as relações entre eles". E como instrumento de coleta de dados, utilizamos um questionário, pois, conforme Cervo e Berviam (2006, p.48), "O questionário é a forma utilizada mais ousada para coletar dados, pois possibilita medir com melhor exatidão o que se deseja [...]", quanto à forma, um questionário com perguntas abertas que permitem respostas 


\section{SEMINÁRIO DE PESQUISA EM CIÊNCIAS HUMANAS - SEPECH \\ Humanidades, Estado e desafios didático-científicos \\ Londrina, 27 a 29 de julho de 2016}

livres, com linguagem própria e emissão de opinião, que possibilitará uma investigação mais profunda e precisa (LAKATOS; MARCONI, 1991, p. 48).

O questionário foi aplicado na escola da rede municipal paulista de ensino EMEIEF Governador Mário Covas, situada na cidade de Tupã, com a professora regente S. M. da turma de $2^{\circ}$ ano do Ensino Fundamental, período da manhã. Além disso, realizamos gravação em formato de vídeo, contendo situação de aplicação da atividade didática "Leitura em voz alta" de texto literário realizada pelo professor.

Atualmente, o momento de contar histórias "está presente no "horário nobre" da rotina escolar e não é mais vista como uma atividade sem importância e para preencher o tempo que falta para o término da aula" (GARCIA, n/d, p.3), uma vez que, como afirma Meireles (1979, p.28) "a literatura não é, como tantos supõem, um passatempo".

Dentre as práticas de leitura, a escola tem se preocupado em apresentar o livro para o aluno por meio da leitura pelo professor na sala de aula, pois:

Acreditamos no poder que a história tem de provocar emoções e despertar o ouvinte para o fascínio da palavra escrita e da leitura. Sabemos também que a história contada na sala de aula é o elo entre o leitor e o livro, afinal é através das histórias narradas que podemos fazer brotar no ouvinte o desejo de querer ouvir, ler e descobrir outras histórias. Como no dito popular, -uma história puxa a outra. (MICARELLO e FREITAS, 2002, p. 107).

Dessa forma, é importante destacar que a leitura do professor deve ter espaço garantido no dia a dia, o momento de contar histórias deve estar inserido na rotina dos alunos, é pela frequência que eles compreenderão que em determinada hora do dia, é hora de ouvir histórias. É preciso demonstrar para o aluno que esta atividade é tão importante como qualquer outra atividade e por isso está estabelecida na rotina de sala de aula. Neste contato com a leitura "as crianças familiarizam-se com a linguagem escrita, sentem prazer com a leitura. Conhecem uma diversidade de histórias e autores e ampliam suas competências leitoras e o contado com diferentes gêneros de textos" (GARCIA, n/d. p.3).

Podemos compreender, com base em Teberosky e Colomer (2003, p.137) que:

Ao escutar a leitura, as crianças aprendem que a linguagem escrita pode ser produzida, repetida, citada e comentada. Interagir com textos escritos, através da mediação do adulto que lê em voz alta, é um processo de aprendizagem novo para a criança, é adentrar-se em território desconhecido para explorar novas formas de linguagem.

Ao ler para seus alunos, desde o início da escolaridade, o professor propicia o contato fundamental com o acesso à cultura escrita, "é pela voz do professor que se começa a construir um leitor, pois, ao dar voz aos textos, permite não apenas que as crianças tenham acesso à historia lida, mas ao modo como cada um se organiza" (SÃO PAULO, 2014, p. 40).

Silva (1988, p.79) afirma que "a leitura em voz alta realizada pelo professor tem a responsabilidade, e também o privilégio, de incentivar nos alunos o gosto pela leitura, pois - ao ouvir os textos lidos em voz alta, as crianças vão criando 


\section{SEMINÁRIO DE PESQUISA EM CIÊNCIAS HUMANAS - SEPECH \\ Humanidades, Estado e desafios didático-científicos \\ Londrina, 27 a 29 de julho de 2016}

consciência dos aspectos da expressão escrita (...)” e o “(...) gosto de ouvir é como o gosto de ler, portanto, quando o aluno é presenteado com uma boa leitura em voz alta, é apresentado a ele o quão maravilhoso é poder desfrutar-se de uma história escrita" (MEIRELES, 1979, p.42).

Contudo, a atividade de leitura em voz alta possibilita a aprendizagem da linguagem escrita de boa qualidade antes mesmo que tenham compreendido o sistema de escrita, e propicia o contato com textos que as crianças não escolheriam de maneira independente, amplia o repertório de leitura, mas o mais importante é que quando o professor lê para os seus alunos está explicitando seu comportamento leitor. Podemos compreender, com base em Rana (2010, p.2) que:

Comportamentos leitores são conteúdos a serem ensinados. Portanto, o professor precisa ter conhecimento do que venha a ser "comportamento leitor" e colocá-los em prática. Antes de ensinar este conteúdo, ele deve ter claro quais são os objetivos (propósitos) que se quer atingir com a leitura.

Nesse sentido, ressaltamos que:

(...) para comunicar às crianças os comportamentos que são típicos do leitor, é necessário que o professor os encarne na aula, que ofereça a elas a oportunidade de participar de atos de leitura que ele próprio está realizando, que estabeleça com elas uma relação de "leitor para leitor" (LERNER, 2002, p.95).

"Podemos dizer que a figura do professor como leitor e modelo de leitor para seus alunos é uma das experiências escolares mais significativas no processo de formação destes como leitores" (GROTTA, 2001, p.148), e para que isso se torne possível, é preciso que o professor tenha clareza de seus objetivos em ler para seus alunos e prepare a leitura antes de iniciá-la para a turma. A leitura em voz alta é um ato que exige certa responsabilidade, pois ao se colocar como um porta-voz, o professor faz com que, nesse momento, este seja o único contato do aluno com a história (LAJOLO, 2005 , p. 27 e 28 ).

Assim sendo, salientamos que:

O professor que se percebe como mediador da leitura para seus alunos precisa conhecer os fundamentos básicos da Teoria da Leitura, a fim de que sua indicação de textos e de autores faça parte de um processo eficiente de formação e de manutenção de leitores jovens, processo esse baseado em consciência, preparo, conhecimento e competência, isento de mesmices e sensaborias (BARROS, 2006, p.137).

No entanto, para formar leitores é imprescindível que o professor seja um ávido leitor e mostre-se "[...] apaixonado pela leitura, porque é muito dificil que alguém que não sinta prazer com a leitura consiga transmiti-lo aos demais" (SOLE, 1998, p. 9) e proporcione aos alunos experiências com livros e leituras bem planejadas.

Assim, para que os alunos adquiram o gosto por aquilo que estão ouvindo e se sintam envolvidos pela história, é primordial que o professor considere alguns aspectos 


\section{SEMINÁRIO DE PESQUISA EM CIÊNCIAS HUMANAS - SEPECH \\ Humanidades, Estado e desafios didático-científicos \\ Londrina, 27 a 29 de julho de 2016}

e procedimentos, fundamentais, da leitura em voz alta realizada pelo professor, pois para realizar uma boa atividade de leitura para os alunos o professor deve garantir três momentos: antes, durante e depois. Antes da leitura, o professor pode apresentar o contexto de produção: autor, título, portador, gênero e editora e quando necessário trazer informações complementares: ilustrador, ler partes da introdução, informações sobre coleção, etc e usar estratégias de antecipações (o que vocês acham que irá acontecer nesta história?) e explicitar os seus critérios de escolha. Durante a leitura: o professor cuida para que todos os alunos possam ouvi-lo, lendo em voz alta e clara, apresentando sua leitura pessoal, envolvendo o leitor e colocando em jogo seu próprio comportamento leitor. É importante que o professor não interrompa a leitura para explicar palavras, deixando que elas descubram o significado a partir do contexto. Depois da leitura: o professor deve tecer comentários sobre o que foi lido, opinando, trocando pontos de vista, expondo os seus, e o mais importante instigar as crianças a falarem acerca de suas impressões, voltar e ler trechos para possibilitar maior compreensão ou prazer na interação com o texto ou confirmar e retificar as interpretações sugeridas.

\section{ENTREVISTA REALIZADA COM A PROFESSORA REGENTE E ANÁLISE}

1) Em sua opinião, o que é uma atividade de leitura em voz alta realizada pelo professor?

Uma atividade de leitura em voz alta pelo professor é aquela onde o mesmo realiza todos os dias, de preferência no início da aula e sua posição na sala de aula deve ser central.

2) Você considera a prática de leitura em voz alta importante? Por quê?

Sim, a leitura em voz alta faz com que os alunos aprendam essa prática através do trabalho modalizador do professor, além de despertar o interesse das crianças em aprender sobre os vários gêneros literários, despertando a imaginação.

3) A leitura em voz alta pode ser realizada em uma classe de alfabetização? Por quê?

Com certeza a leitura em voz alta deve ser realizada em uma classe de alfabetização. Aliás, deve ser realizada também desde a educação infantil para com isso desenvolver o gosto das crianças pela leitura e a oralidade.

4) O que os alunos aprendem com essa atividade?

Os alunos, além de conhecer os vários tipos de gêneros, conseguem desenvolver através do papel modelizador do professor a oralidade e a apreciação de boas leituras.

5) A leitura em voz alta é uma atividade permanente em sua rotina? Qual o critério você utiliza para selecionar os livros que lê?

Sim, costumo usar como critério na escolha dos livros: conhecer os interesses, os problemas e o momento em que as crianças estão vivendo. Busco então contextualizar as leituras com a realidade apresentada.

6) Se a resposta à pergunta anterior foi sim, a partir de que momento a leitura em voz alta passou a fazer parte de sua rotina escolar? E o que mudou?

Desde que iniciei o meu trabalho como professora (5anos), faço as leituras em voz alta. As mudanças foram muitas principalmente no momento em que as crianças 


\section{SEMINÁRIO DE PESQUISA EM CIÊNCIAS HUMANAS - SEPECH \\ Humanidades, Estado e desafios didático-científicos \\ Londrina, 27 a 29 de julho de 2016}

escolhem os livros para lerem em casa, fazem a indicação literária e também na oralidade, onde costumam "imitar" os personagens da história e até representá-los.

Por meio desta entrevista, foi possível observar que a professora reconhece as finalidades e o que os alunos aprendem com esta atividade, realizando-a como atividade permanente de alfabetização. Demonstra conhecimento e domínio sobre a prática leitura em voz alta feita pelo professor, quando aborda com clareza a importância e a eficácia de desenvolver com destreza esta prática rica e fundamental no desenvolvimento dos alunos. A professora demonstra compreender que é por meio do papel modelizador do professor que os alunos aprendem o comportamento leitor, assim como realizar esta prática diariamente em qualquer ambiente escolar, para que desde pequenos desenvolvam o gosto pela leitura e aprendam a apreciar boas histórias. Ela destaca a necessidade da expressividade (sonoridade das palavras, recursos de linguagem, como a rima o ritmo, etc.), enfatizando que os alunos oralmente imitam ou representam os personagens.

O processo de formação continuada no qual a professora está envolvida na unidade escolar subsidia as fundamentações teóricas observadas em seu discurso. Desta forma, o direcionamento de uma nova prática que desenvolva o trabalho efetivo com a literatura infantil acontece em decorrência do processo de formação contínua, do estudo pessoal, do planejamento e materiais didáticos. Observamos que a coerência entre o discurso e a prática fundamentados teoricamente, com as condições didáticas e pedagógicas necessárias resultam no trabalho expressivo com a literatura infantil nas escolas.

Observa-se que o critério de escolha da professora está atrelado à concepção utilitária de texto literário, visto que a mesma os problemas e o momento em que as crianças estão vivenciando. Por fim, em devolutiva à professora ressaltaria apenas que uma das finalidades desse momento é possibilitar ao aluno o aprendizado de recursos utilizados para a escolha de suas próprias leituras - autor, gênero, editora, ilustrações, entre outros - ampliando o repertório cultural e o contato dos alunos com textos que não escolheriam de maneira independente e assim também possibilitar o contato dos mesmos com textos em linguagem escrita de boa qualidade.

\section{PLANO DE AULA}

Objetivos

- Desenvolver a capacidade linguística (ampliação de vocabulário);

- Desenvolver a imaginação e a compreensão de textos;

- Desenvolver a capacidade de ouvir o outro;

- Possibilitar ao aluno o aprendizado de recursos utilizados para a escolha de suas próprias leituras (autor, gênero, editora, ilustrações, entre outros);

- Ampliar o repertório cultural e o contato dos alunos com textos que não escolheriam de maneira independente;

- Possibilitar o contato dos alunos com textos em linguagem escrita de boa qualidade; 


\section{SEMINÁRIO DE PESQUISA EM CIÊNCIAS HUMANAS - SEPECH \\ Humanidades, Estado e desafios didático-científicos \\ Londrina, 27 a 29 de julho de 2016}

- Expor ao aluno seu comportamento leitor, apresentando seu critério de escolha, apreciação das obras, entre outros;

- Criar o hábito nos alunos de ler desde as séries iniciais.

Conteúdos

- Livro escolhido: Contos de enganar a morte

- Conto: O homem que enxergava a morte

- Autor: Ricardo Azevedo

Ano

- Gênero: Contos de artimanha

- $2^{\circ}$ Ano A

- Período da manhã

- Escola: EMEIEF Governador Mário Covas

Tempo estimado

- 1 (uma) aula

Material necessário

- Livro

Desenvolvimento

Antes

A professora irá anunciar a leitura a ser feita, informando que este momento será gravado. Em seguida, irá explicitar os motivos da escolha (por se tratar de um assunto delicado para as crianças, onde com certeza eles não o escolheriam de maneira independente) e apresentar o contexto de produção: autor, título, portador, gênero e a editora. Usar estratégias de antecipação: o que vocês pensam em relação à morte? É possível enganá-la? $O$ que seriam das crianças que nascem se as pessoas não morressem, existiria lugar para todos? Em se tratando do livro e do conto de artimanha onde este deve ter um problema, um bobo e um esperto, quem é o bobo? E o esperto? Qual o problema? Será que o homem que enxergava a morte conseguiu enganá-la? Por quanto tempo, de que maneira? Quem arrisca prever o final do conto?

Durante

Durante a leitura não serão feitas interrupções para explicar palavras. Depois

Tecer comentários sobre o que foi lido, instigando as crianças para que façam o mesmo, opinando, trocando pontos de vistas, se necessário voltar e ler alguns trechos para possibilitar maior compreensão.

\section{ANÁLISE GERAL DA TRANSCRIÇÃO DA MODALIDADE DIDÁTICA DE LEITURA EM VOZ ALTA}

Para análise geral da situação de aprendizagem consideramos todo o processo realizado com a professora regente para o desenvolvimento da atividade na sala de aula: a entrevista, o planejamento da aula, transcrição e análise dos procedimentos.

Desta forma, é fundamental atentarmos para os objetivos da leitura em voz alta realizada pelo professor, as propostas de procedimentos elencadas para serem realizadas pela professora regente, bem como a comparação do que foi planejado no "antes, durante e depois" com a interação na prática. 


\section{SEMINÁRIO DE PESQUISA EM CIÊNCIAS HUMANAS - SEPECH \\ Humanidades, Estado e desafios didático-científicos \\ Londrina, 27 a 29 de julho de 2016}

Nesta perspectiva, consideramos a atividade como uma boa situação de aprendizagem, na qual a professora conduziu muito bem sua aula, contemplando a maior parte dos procedimentos da leitura em voz alta necessários, garantindo o "antes, durante e depois". Proporcionando aos alunos um momento significativo de aprendizagem, como formadora de leitores, a professora não apenas leu o livro, mas sim mediou a situação para que os alunos adquirissem capacidades de compreensão e de apreciação entre outras necessárias para um bom leitor, inserindo as crianças no mundo da leitura.

A escolha do livro foi fundamental, a professora prezou pela qualidade literária, escolhendo um texto que estimulou os alunos a ouvirem a história, um assunto que está presente no cotidiano de todos os seres humanos, já que, "não é interessante escolher livros pela "mensagem moral" que a história carrega, mesmo que traduza valores muito prezados atualmente" (SÃO PAULO, 2014, p.44), tais ensinamentos não podem ser o critério de escolha do professor, este deve sempre prezar pela qualidade literária.

Ao ouvir histórias as crianças estão em contato com uma linguagem diferente da usada no cotidiano, e essas experiências linguísticas proporcionam um enriquecimento grandioso no vocabulário dos pequenos, por isso, “(...) é preciso evitar os textos em que a linguagem é empobrecida, pois é lidando com um vocabulário mais rico que as crianças realmente ampliarão suas possibilidades linguística" (SÃO PAULO, 2014, p.44).

Garantindo os procedimentos, a professora apresentou o autor aproximando os alunos de sua obra literária e como já faz parte de sua rotina retomou alguns dos textos que ela já leu para eles.

No momento da atividade, a professora realizou a leitura com ênfase para dar vida ao texto, com entonações, pausas, tom de voz, ritmo, bem como gestos adequados no desenrolar da aula; durante seu planejamento buscou ampliar sua compreensão do texto para expressar suas próprias impressões para os alunos.

Conduziu bem a gestão, pois organizou a sala de aula, ressaltando a importância do silêncio para oportunizar o envolvimento de todos.

Colocar o aluno em contato com o livro, no final da leitura, ou durante a leitura, é estimulante, e faz com que os alunos aprendam a observar as ilustrações das histórias, e a relacionarem com aquilo que foi contado.

Ao selecionar um livro para ler para sua sala, o professor utiliza vários critérios, e esses critérios precisam ser informados para o aluno, no momento em que ele irá ler, para que ao longo do tempo, as crianças, também se vejam como leitores que podem explicitar suas preferências pessoais.

A atividade permite que o professor amplie alguns procedimentos, tais como, no início da leitura, acreditamos que a professora poderia ter investido mais na conversa sobre o título e oportunizado a fala de mais alunos, assim algumas questões ficariam sem respostas, para que no final da leitura, pudessem voltar nelas e checar a compreensão. É sempre importante, convidar os alunos a dizer o que pensam ou sentiram quando ouviram a história, "no início tais comentários são bastante simples, mas com o tempo tendem a ganhar qualidade, especialmente se contarem para isso com intervenções do professor" (SÃO PAULO, 2014, p.45).

A fala sobre o gênero, também, poderia ter enriquecido mais a conversa, os contos de artimanha são histórias engraçadas, em que um dos personagens sempre consegue enganar o outro, levando a melhor. "Essas histórias são interessantes porque 


\section{SEMINÁRIO DE PESQUISA EM CIÊNCIAS HUMANAS - SEPECH \\ Humanidades, Estado e desafios didático-científicos \\ Londrina, 27 a 29 de julho de 2016}

permitem explicitar as crianças que, nos contos, há uma diferença entre as ações dos personagens e suas intenções. Ao perceber que o personagem diz algo, mas o faz para enganar o outro, as crianças começam a diferenciar esses dois níveis das narrativas". (SÃO PAULO, 2014, p.43).

Enfim, acreditamos que para que a atividade, verdadeiramente, resulte em uma aprendizagem para o aluno, o professor deve agir com intencionalidade, tendo em mente os objetivos de se trabalhar com o livro e a leitura na sala de aula, entendendo a importância que desempenha para formar verdadeiros leitores.

\section{CONSIDERAÇÕES FINAIS}

Abordamos, neste trabalho, temática de suma importância: o domínio da leitura, que implica em vários fatores relevantes no cotidiano escolar. Buscamos refletir sobre o percurso histórico da leitura em voz alta, o que contribuiu para compreendermos as mudanças nas concepções do ensino da leitura. Consideramos as diversas modalidades didáticas, bem como as estratégias e metodologias eficazes para o desenvolvimento da atividade com os alunos.

Ensinar é uma tarefa que impõe desafios diários e variados para o professor, implica no planejamento de boas intervenções e busca constante de conhecimentos e procedimentos que contribuam para a aprendizagem significativa de seus alunos. Uma vez que ele, a escola, o aluno e a família são advindos de contextos diferentes, gerando conflitos e dificuldades diversas. Quando o educador consegue contextualizar sua atividade, envolvendo as vivências de seus educandos nesta busca de saberes, mediando para que adquiram as capacidades necessárias para a participação social e pleno exercício da cidadania, consegue, de fato, proporcionar uma boa situação de aprendizagem.

Assim, focamos nossa pesquisa na leitura em voz alta realizada pelo professor porque estando contemplada diariamente na rotina do professor, torna-se importante prática para o docente e um excelente instrumento para desenvolver nos alunos $\mathrm{o}$ comportamento leitor e estimulá-los para o hábito de ler.

Durante a pesquisa de campo, constatamos que a leitura em voz alta realizada pelo professor correlaciona-se diretamente às condições didáticas e as intervenções do professor no momento da leitura, considerando o fato de que, a formação é contínua, pois, não existe uma fórmula específica para o sucesso da atividade. Com isso, verificamos que por meio dessa prática, o aluno aprende a selecionar bons livros e ampliar o seu próprio repertório, desde que tenha um professor como leitor fluente e um bom modelo a ser seguido.

Por fim, concluímos que o prazer pela leitura é desenvolvido principalmente no âmbito escolar. Com a leitura em voz alta realizada pelo professor, o aluno aprende a selecionar o que vai ler, a posicionar-se diante dos valores e conceitos veiculados nos textos e a apreciar ou não os diversos gêneros, bem como utilizar recursos que os possibilitam compreender, interpretar e interagir com a mensagem, contexto ou autor. Com o exemplo do professor, o aluno aprimora cada vez mais sua capacidade de ajustar os procedimentos de leitura as diversas finalidades e necessidades impostas pela sociedade. Procuramos, neste trabalho, demonstrar que "a leitura em voz alta bem 


\section{SEMINÁRIO DE PESQUISA EM CIÊNCIAS HUMANAS - SEPECH \\ Humanidades, Estado e desafios didático-científicos \\ Londrina, 27 a 29 de julho de 2016}

conduzida pode ser determinante para criar novos desejos nos leitores" (JEAN, 2000, p. 21).

\section{REFERÊNCIAS}

GARCIA. M. A leitura em voz alta feita pelo professor como tema de pesquisa didática: $O$ que os alunos podem aprender com isso. Disponível em: $<\mathrm{http}$ ://veracruz.edu.br/doc/ise/ise_19cole_congresso_leitura_brasil_julho.pdf $>$. Acesso em: 24 out. 2015.

JEAN, G. A leitura em voz alta. Lisboa: Instituto Piaget, 2000.

MARCONI, M. A; LAKATOS, E. M. Fundamentos de metodologia científica. $3^{\text {a }}$. ed. São Paulo: Editora Atlas, 1991.

MEIRELES, C. Problemas da literatura infantil. Direção de Fany Abramovich. 2a . ed. São Paulo: Summus, 1979.

SÃO PAULO. Secretaria da Educação. Ler e Escrever: guia de planejamento e orientações didáticas; professor alfabetizador $-1^{\circ}$ ano. $4^{\mathrm{a}}$ ed. rev. e atual. São Paulo: FDE, 2014.

SILVA, E. T. Elementos de pedagogia da leitura. São Paulo: Martins Fontes, 1988.

TEBEROSKY, A.; COLOMER, T. Aprender a ler e a escrever: uma proposta construtivista. Porto Alegre, Artmed, 2003. 